\title{
Effect of Cytoskeletal Disruption on Mechanotransduction of Hydrostatic Pressure by C3H10T1/2 Murine Fibroblasts
}

\author{
Joon W. Shim ${ }^{1}$, Dwayne A. Wise ${ }^{2}$ and Steven H. Elder ${ }^{* 1}$ \\ ${ }^{1}$ Agricultural \& Biological Engineering, Mississippi State University, Starkville, MS, USA \\ ${ }^{2}$ Biological Science, Mississippi State University, Starkville, Mississippi, USA
}

\begin{abstract}
Cyclic hydrostatic pressure of physiological magnitude (<10 MPa) stimulates chondrogenic differentiation of mesenchymal stem cells, but mechanotransduction mechanisms are not well understood. It was hypothesized that an intact cytoskeleton would be required for uninhibited mechanotransduction of hydrostatic pressure. Therefore we examined the effects of drugs which selectively interfere with actin and tubulin polymerization on pressure-induced upregulation of aggrecan and col2a1 (type II collagen) mRNA expression. C3H10T1/2 cells were cultured as pellets in either $4 \mu \mathrm{M}$ cytochalasin D or $4 \mu \mathrm{M}$ nocodazole and subjected to 3 days of cyclic hydrostatic compression (1 Hz, $5 \mathrm{MPa}, 2 \mathrm{~h}$ per day). Phalloidin staining and indirect immunostaining with anti $\alpha$-tubulin antibody confirmed disruption of microfilament and microtubule assemblies, respectively. Real time RT-PCR revealed that both drugs substantially lowered the basal level of aggrecan and col2a1 mRNA, but that neither drug prevented a pressure-stimulated increase in gene expression relative to the altered basal state. Thus upregulation of macromolecular gene expression by cyclic hydrostatic pressure did not require a completely intact cytoskeleton.
\end{abstract}

Keywords: Mechanotransduction, hydrostatic pressure, cytoskeleton, aggrecan, collagen type II.

\section{INTRODUCTION}

It has been shown that intermittent application of 0.1-10 MPa hydrostatic pressure stimulates chondrogenic differentiation of mesenchymal stem cells, as evidenced by increased mRNA expression of genes such as aggrecan, type II collagen, and Sox 9 and increased production of cartilaginous extracellular matrix macromolecules [1-6]. However, the mechanism(s) of hydrostatic pressure mechanotransduction is not well understood. Typically occupying $16-21 \%$ of a cell's volume [7] and linked to extracellular matrix elements, the cytoskeleton is often implicated in mechanotransduction of cellular distortion (e.g. stretch). However, its role in transduction of hydrostatic pressure has not been fully characterized. Because hydrostatic pressure can be a major factor in chondroinduction of mesenchymal stem cells, it was proposed to investigate the importance of the cytoskeleton in transduction of hydrostatic pressure by $\mathrm{C} 3 \mathrm{H} 10 \mathrm{~T} 1 / 2$ murine fibroblasts, a model of primary bone marrow mesenchymal stem cells. Any cell undergoing division will have an altered cytoskeleton, and the cytoskeleton itself may become a target for therapeutic agents designed to interfere with cell division (e.g., anti-cancer drugs). Thus this area of research may have basic science and clinical relevance.

In primary bovine chondrocytes subjected to $5 \mathrm{MPa}$ of cyclic hydrostatic pressure the actin stress fibers resembled those of non-pressurized controls. However, as the amplitude of cyclic loading was increased to 15 and $30 \mathrm{MPa}$, the structure of actin fibers was severely affected by the pressure

\footnotetext{
*Address correspondence to this author at the Agricultural \& Biological Engineering, Mississippi State University, P.O. Box 9632, MS 39762, USA; Tel: 662-325-3282; Fax: 662-325-3853; E-mail: selder@abe.msstate.edu
}

while no change was detected in staining patterns of the intermediate filament vinculin [8]. It has also been reported that nocodazole and taxol, a microtubule depolymerizer and stabilizer, respectively, both prevented hydrostatic pressureinduced stimulation of proteoglycan synthesis in chondrocytes [9]. Higher magnitudes of continuous hydrostatic pressure ( $\geq 24 \mathrm{MPa}$ ) substantially suppressed proteoglycan synthesis [10] and caused major changes in the distribution of actin and tubulin similar to those typical of osteoarthritic chondrocytes [11].

It was hypothesized that an intact cytoskeleton would be essential for hydrostatic pressure to elicit an upregulation of cartilage marker gene mRNA by C3H10T1/2 murine fibroblasts. We adopted a conventional approach of using drugs that depolymerize specific cytoskeletal components. Cytochalasin D, a drug that inhibits actin-filament polymerization and can affect cell shape and deformation under stress [12, 13], was used to investigate the importance of the actin microfilaments. Cytochalasin D collapses the actin filament network and destroys microfilament organization. However, it does not significantly alter tubulin (microtubule) or vimentin (intermediate filament) architecture. The importance of microtubules was investigated using nocodazole, an antineoplastic agent which selectively depolymerizes microtubules by binding to tubulin. The purpose of this study was to determine the effects of cytochalasin D and nocodazole on hydrostatic pressure-induced upregulation of aggrecan and col2a1 mRNA by $\mathrm{C} 3 \mathrm{H} 10 \mathrm{~T} 1 / 2$ murine fibroblasts. The C3H10T1/2 cell line is capable of undergoing chondrogenic, osteogenic, myogenic, and adipogenic differentiation [14-17], and the differentiation pathway is strongly influenced by the culture conditions. Chondrogenesis is favored when cells are grown at high density in the presence of transforming growth factor beta-1 [18] or bone morphogenetic protein-2 [19]. 


\section{METHODS}

\section{Cell Culture}

C3H10T1/2 mouse embryonic fibroblasts clone 8 cells (CCL-226, American Type Culture Collection, Manassas, VA) were propagated in standard $75 \mathrm{~cm}^{2}$ polystyrene tissue culture flasks. Unless indicated otherwise, culture medium and supplements were from Sigma (St. Louis, MO, USA). Growth medium contained high glucose $(4,500 \mathrm{mg} / \mathrm{l})$ Dulbecco's Modified Eagle Medium (DMEM), 10\% fetal bovine serum, and $1 \%$ antibiotic/antimycotic solution. Prior to reaching confluence, cells were subcultured using trypsin. In accordance with the donor's recommendation that the line be used between the 5 th and 15 th passages, cells between passage 5 and 7 were trypsinized and resuspended at $5 \times 10^{5}$ cells $/ \mathrm{ml}$. One milliliter aliquots of this suspension were added to $1.5 \mathrm{ml}$-microcentrifuge tubes and pellets formed by brief $(\sim 10 \mathrm{~s})$ centrifugation at $10,400 \mathrm{rpm}$. After allowing 48 $\mathrm{h}$ for pellet consolidation at $37^{\circ} \mathrm{C}$, pellets were transferred to $2 \mathrm{ml}$ screw-top glass vials containing growth medium with $25 \mathrm{ng} / \mathrm{ml}$ recombinant human bone morphogenetic protein-2 (Wyeth Pharmaceuticals, Cambridge, MA, USA) and 50 $\mu \mathrm{g} / \mathrm{ml}$ ascorbic acid and incubated for an additional $24 \mathrm{~h}$. Drugs were then added (see Experimental Design) and the vials sealed with flexible, PTFE-lined silicone rubber septa (P. J. Cobert Associates, St. Louis, MO, USA), so as to exclude all air. Each vial contained 2 or 3 pellets.

\section{Experimental Design}

Vials were assigned to one of the following treatment groups: Control (no load, no drug), CSK Disrupted (no load, with drug), Pressure (with hydrostatic pressure, no drug), and Combined (with hydrostatic pressure, with drug). Vials in the CSK Disrupted and Combined groups contained either $4 \mu \mathrm{M}$ cytochalasin $\mathrm{D}$ or $4 \mu \mathrm{M}$ nocodazole, whereas vials in the other 2 groups contained the same medium without drug. Vials in the Pressure and Combined groups were subjected to cyclic hydrostatic pressure for $2 \mathrm{~h}$ on each of 3 consecutive days: a $1 \mathrm{~Hz}$ sinusoidal waveform with consistent minimum and maximum magnitudes of 0.4 and $5 \mathrm{MPa}$. The experiment was repeated once and the data pooled such that 6 independent samples ( 2 pellets per sample) were analyzed for mRNA expression. The custom pressure chamber consisted of a domed, flanged stainless steel base and lid bolted together to compress a Teflon ${ }^{\circledR}$ gasket $[20,21]$. The waterfilled chamber was pressurized via a flexible hose connected to a hydraulic cylinder mounted in a servohydraulic testing machine (Bionix 858, MTS, Minneapolis, MN, USA). During loading vials in the Control and Drug groups were placed in a separate non-pressurized water-filled chamber. Both chambers were immersed in the same $37^{\circ} \mathrm{C}$ water tank. Temperature was regulated via CSC32 digital controller (Omega Engineering Inc., Stamford, CT, USA) with thermocouple feedback and 500W immersion heater. Water in the tank was continuously circulated by a 230 gallon/h submersible pump.

\section{Total RNA Isolation}

Immediately after the endpoint of the entire 3-day loading session, all vials were removed from their respective chambers and two cell pellets from each vial were placed immediately in $1 \mathrm{ml}$ of RNA stabilization solution (RNAlater ${ }^{\mathrm{T}}$, Qiagen Inc., Valencia CA, USA). For those glass vials containing three pellets, the third pellet was reserved for cytoskeletal imaging. Total RNA was isolated using the RNeasy ${ }^{\circledR}$ Mini kit (Qiagen Inc., Valencia, California, CA, USA). Concentration and purity of the eluted RNA was measured by reading absorbance at 260 and $280 \mathrm{~nm}$ in a spectrophotometer (SPECTRONIC 601, Bausch \& Lomb, Rochester NY or ND-1000 Spectrophotometer, NanoDrop Technologies, Wilmington DE).

\section{Primer Sequence and qRT-PCR}

PCR primers (Table 1) for mouse glyceraldehyde 3phosphate dehydrogenase (GAPDH) as a housekeeping gene and those for aggrecan and collagen, type II, alpha 1 (col2a1) were designed using Primer3 (v 0.4.0) online software [22]. Real Time quantitative reverse transcription polymerase chain reaction (qRT-PCR) was carried out to quantify the relative mRNA expression of genes of interest in experimental groups relative to controls. Thermal cycling and real-time detection of fluorescent cDNA was performed in an iCycler iQ $^{\circledR}$ (Bio-Rad, Hercules, CA, USA). Reverse transcription and reverse polymerase chain reactions were performed using the iScript One-Step RT-PCR kit with SYBR $^{\circledR}$ Green (Bio-Rad, Hercules, CA, USA). Thermal cycling parameters were as follows: $10 \mathrm{~min}$ at $50^{\circ} \mathrm{C}$ for cDNA synthesis, $5 \mathrm{~min}$ at $95^{\circ} \mathrm{C}$ for iScript reverse transriptase inactivation, $10 \mathrm{sec}$ at $95^{\circ} \mathrm{C}$ and $30 \mathrm{sec}$ at $55^{\circ} \mathrm{C}$ for PCR cycling and detection for 40 cycles. Then, melt curve analysis composed of $1 \mathrm{~min}$ at $95^{\circ} \mathrm{C}, 1 \mathrm{~min}$ at $55^{\circ} \mathrm{C}$ and $10 \mathrm{sec}$ at $55^{\circ} \mathrm{C}$, was performed to confirm specificity of product. Load- and drug-induced fold changes in the genes of interest were calculated using the $\Delta \Delta \mathrm{C}_{\mathrm{T}}$ method [23], and data were statistically analyzed by two-way ANOVA at the $95 \%$ confidence level $(\alpha=0.05)$.

\section{Cytoskeletal Imaging}

Pellets to be used in cytoskeletal imaging studies were equilibrated in buffer PEM (100 mM PIPES, pH 6.9; $1 \mathrm{mM}$ $\mathrm{MgCl} 2 ; 1 \mathrm{mM}$ EGTA) with $4 \%$ polyethylene glycol (MW $40,000)$. They were then fixed for $2 \mathrm{~h}$ in PEM containing 3\%

Table 1. Sequences of Primers Used for qRT-PCR

\begin{tabular}{|c|l|c|c|}
\hline Primer & Sequence & Product Size & Genbank Accession Number \\
\hline \hline GAPDH & $\begin{array}{l}\text { (forward) 5'-CTGAGGACCAGGTTGTCTCC-3' } \\
\text { (reverse) 5'-GCCTCTCTTGCTCAGTGTCC-3' }\end{array}$ & 226 bp & M32599 \\
\hline COL2A1 & $\begin{array}{l}\text { (forward) 5'-GCCAAGACCTGAAACTCTGC-3' } \\
\text { (reverse) 5'-GCCATAGCTGAAGTGGAAGC-3' }\end{array}$ & 239 bp & NM_031163 \\
\hline Aggrecan & $\begin{array}{l}\text { (forward) 5'-CTCAGTGGCTTTCCTTCTGG-3' } \\
\text { (reverse) 5'-CTGCTCCCAGTCTCAACTCC-3' }\end{array}$ & L07049 bp \\
\hline
\end{tabular}


formaldehyde followed by $1 \mathrm{~h}$ permeabilization in PEM containing $0.5 \%$ Triton $\mathrm{X}-100$ and $30 \mathrm{~min}$ digestion in $1 \mathrm{mg} / \mathrm{ml}$ hyaluronidase in $\mathrm{PBS}$ at $37^{\circ}$. For visualization of microfilaments, pellets were stained for $1 \mathrm{~h}$ with Alexafluor 488labeled phalloidin (Molecular Probes, Eugene, OR, USA) diluted 1:40 in PBS containing 1\% bovine serum albumin. For visualization of microtubules, indirect immunostaining with anti $\alpha$-tubulin antibody was performed. Pellets were incubated overnight at $4^{\circ} \mathrm{C}$ with monoclonal anti $\alpha$-tubulin antibody (clone DM1A, Sigma-Aldrich, St. Louis MO, USA) diluted 1:500 in PBS with 1\% BSA. They were then rinsed extensively in PBS and incubated for $1 \mathrm{~h}$ in fluorescein isothiocyanate-conjugated secondary $\operatorname{IgG}$ antibody diluted 1:25 in PBS. Both phalloidin and immunostained pellets were thoroughly rinsed in PBS to reduce background and were then examined by confocal laser scanning microscopy.

\section{RESULTS}

Pressure generated within the chamber was calculated by dividing the force (as recorded from $25 \mathrm{kN}$ load cell) by the hydraulic cylinder bore area of $958 \mathrm{~mm}^{2}$. The minimum and maximum applied hydrostatic compressive stresses of 0.4 and $5 \mathrm{MPa}$ were maintained consistently over the $2 \mathrm{~h}$ duration of cyclic pressurization at $1 \mathrm{~Hz}$. Glass vials in which the cultures were sealed contained only very small, if any, entrapped air bubbles, so that pressure was transmitted instantaneously to the inside of the vials. The MTS actuator stroke necessary to achieve the desired pressure was approximately $15 \mathrm{~mm}$. At the end of a loading session, the temperatures inside the experimental and control chambers were within $0.2^{\circ} \mathrm{C}$ of the external bath, which was maintained at $37 \pm 0.2^{\circ} \mathrm{C}$.

\section{Gene Expression}

All melt curves exhibited a single sharp peak indicating the presence of primer-specific amplicons. The difference between $\mathrm{C}_{\mathrm{T}}$ values of technical replicates was always less than 0.4. The GAPDH housekeeping gene's $C_{T}$ value was 12-14, and the standard deviation of biological replicates was less than 0.5. $\mathrm{C}_{\mathrm{T}}$ values for Aggrecan and col2a1 were in the range of 18-25, and standard deviations of biological replicates were less than 1 . Fold changes in mRNA expression are reported as mean \pm standard deviation (Figs. 1-3). In the absence of cytoskeleton-altering drugs, cyclic hydrostatic pressure caused a $2.26 \pm 0.71$-fold upregulation of aggrecan mRNA $(\mathrm{p}=0.0028)$ and a $1.72 \pm 0.51$-fold increase in col2al mRNA $(p=0.0055)$ (Pressure vs. Control). Treatment with either drug alone had the opposite effect. Aggrecan mRNA was downregulated by $0.67 \pm 0.19$-fold $(\mathrm{p}=$ $0.0048)$ and col $2 \mathrm{a} 1$ by $0.34 \pm 0.11$-fold $(\mathrm{p}=0.0003)$ in response to treatment by cytochalasin (CSK Disrupted vs. Control). Nocodazole decreased aggrecan mRNA by $0.35 \pm$ 0.22 -fold $(\mathrm{p}=0.0007)$ and col2a1 mRNA by $0.27 \pm 0.17$ fold $(\mathrm{p}=0.0003)$ (CSK Disrupted vs. Control). However, neither drug significantly diminished the pressure-induced upregulation of either aggrecan or col2a1 above the druglowered baseline. In the presence of $4 \mu \mathrm{M}$ cytochalasin-D, hydrostatic pressure induced a $1.54 \pm 0.42$-fold increase in aggrecan mRNA and a $2.07 \pm 0.56$-fold increase in col2a1 (Combined vs. CSK Disrupted). These fold increases were not statistically different from those induced by Pressure relative to Control. Similarly, pressure increased aggrecan mRNA by $1.79 \pm 0.75$-fold and col2a 1 mRNA by $1.64 \pm$ 0.30 -fold in the presence of $4 \mu \mathrm{M}$ nocodazole (Combined vs. CSK Disrupted). These effects were not statistically different from those produced by Pressure relative to Control.

\section{Pressure vs. Control}

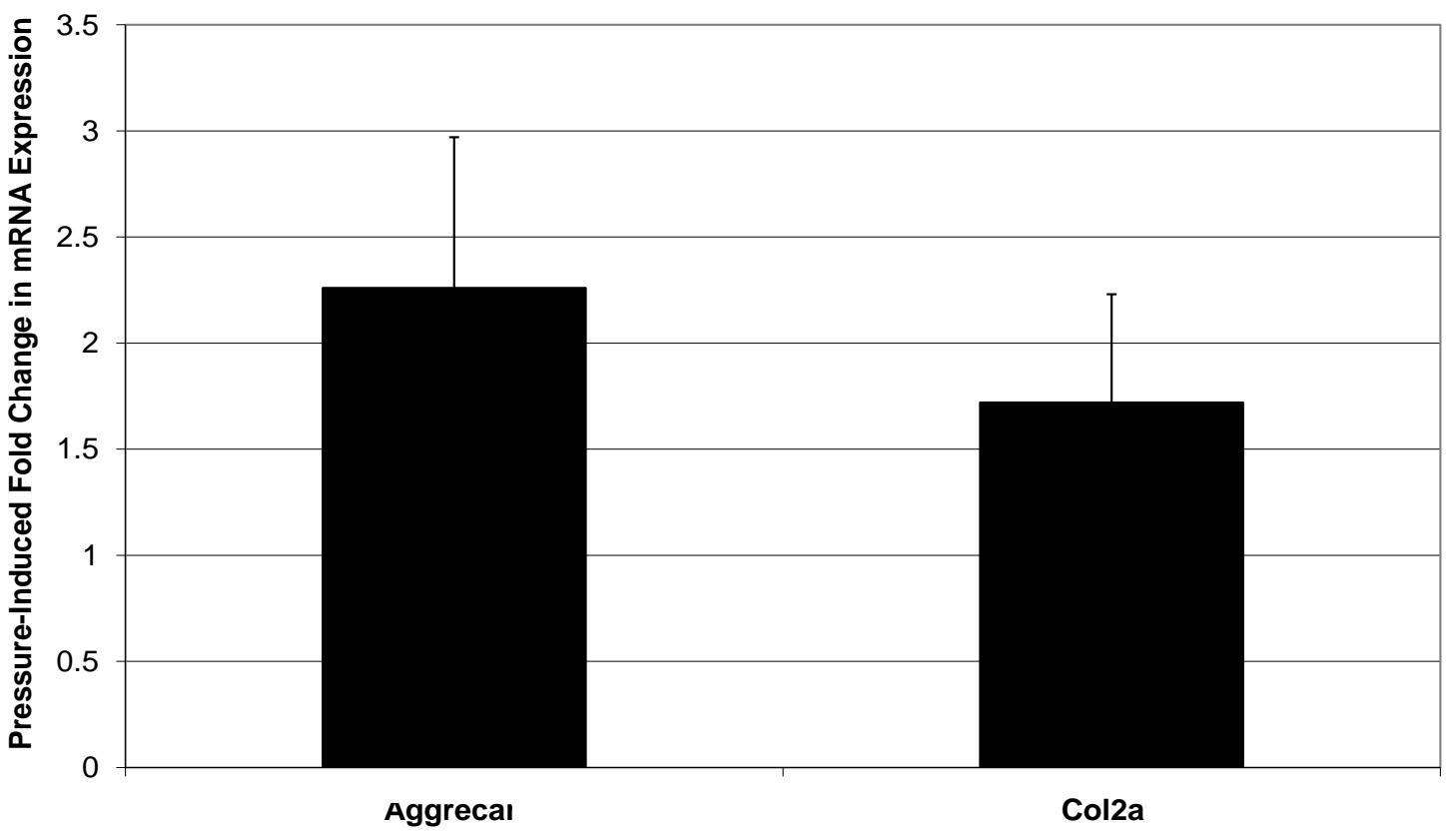

Fig. (1). Effect of cyclic hydrostatic pressure on mean aggrecan and col2a1 mRNA expression in C3H10T1/2 murine fibroblasts. Each error bars is one standard deviation. Control is represented by a fold change of 1 . Pressure had a statistically significant effect on the expression of both genes relative to Control. 
CSK Disrupted vs. Control

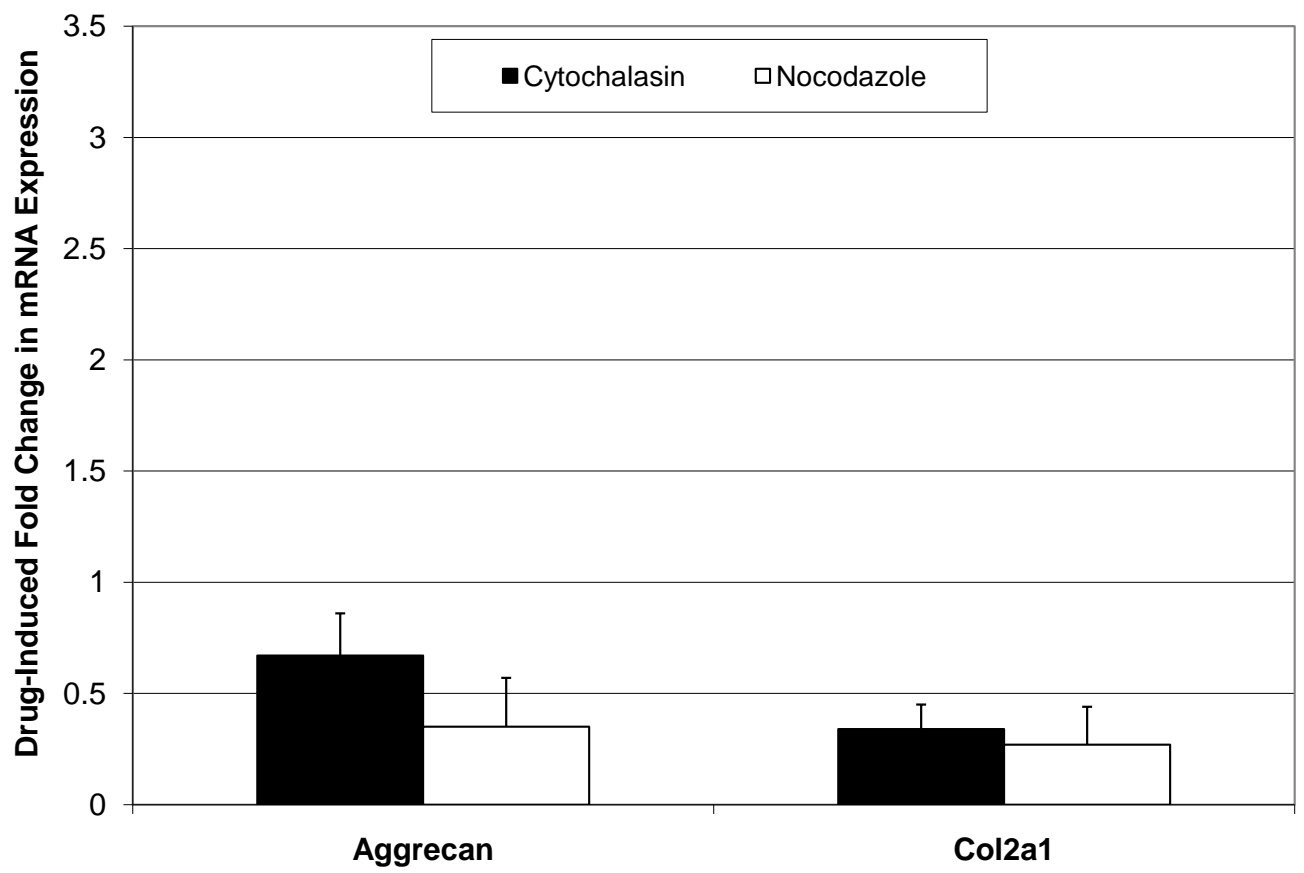

Fig. (2). Effect of cytoskeleton-disrupting drugs on mean aggrecan and col2a1 mRNA expression in C3H10T1/2 murine fibroblasts. Each error bars is one standard deviation. Controls are represented by a fold change of 1. Cytochalasin-D and nocodazole had statistically significant effects on the expression of both genes relative to Control.

\section{Combined vs. CSK Disrupted}

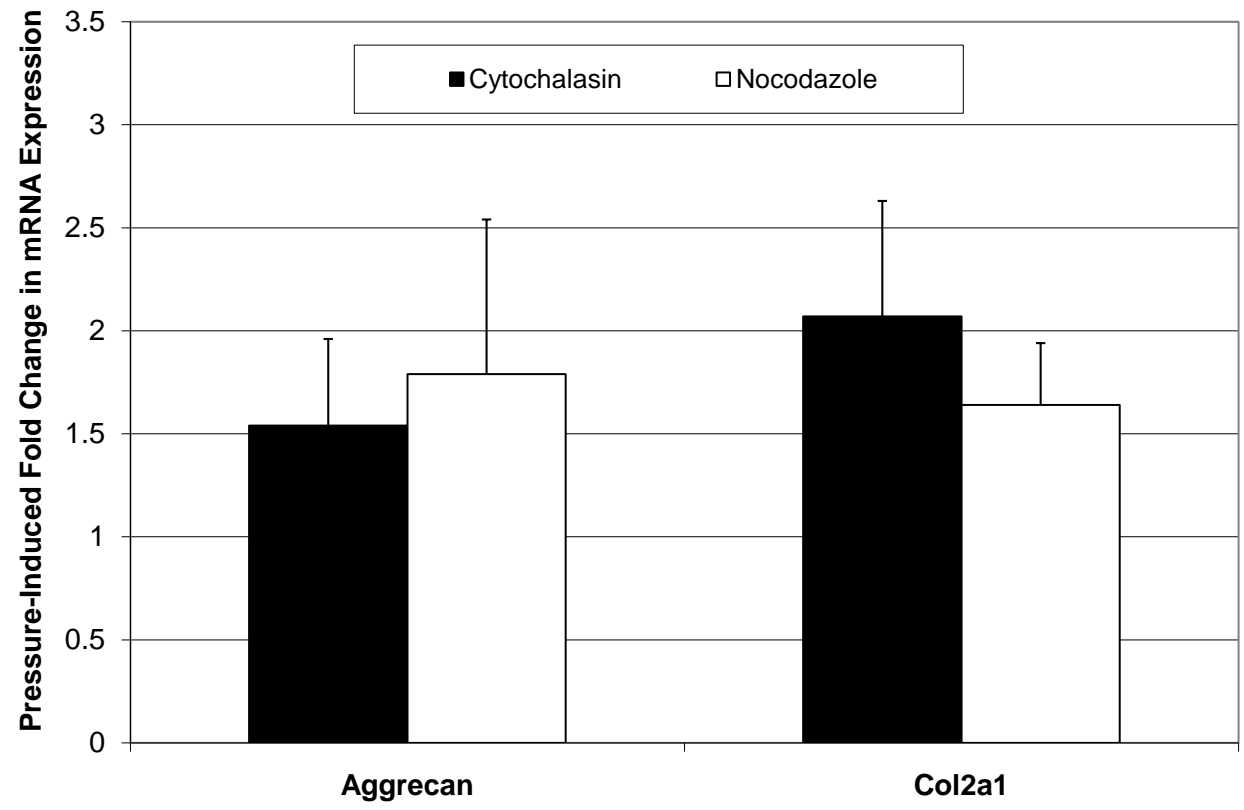

Fig. (3). Effect of cyclicd hydrostatic pressure on mean aggrecan and col2a1 mRNA expression in presence of CSK-disruptive drugs. Each error bars is one standard deviation. The CSK-Disrupted baseline is represented by a fold change of 1 . Pressure had a statistically significant effect on the expression of both genes relative to this CSK-Disrupted baseline. These effects were similar to those of Pessure relative to Control (in the absence of CSK-disruptive drugs).

\section{Visualization of MFs and MTs under Laser Scanning Confocal Microscopy}

Phalloidin staining and indirect immunostaining with anti $\alpha$-tubulin antibody were carried out to visualize microfila- ments and microtubules, respectively (Figs. 4, 5). Each drug had a profound effect on its cytoskeletal target. Specificity of the drugs towards these targets had been confirmed in a pilot study (i.e. no apparent effect of cytochalasin D on microtubules or of nocodazole on microfilaments). Control cells 

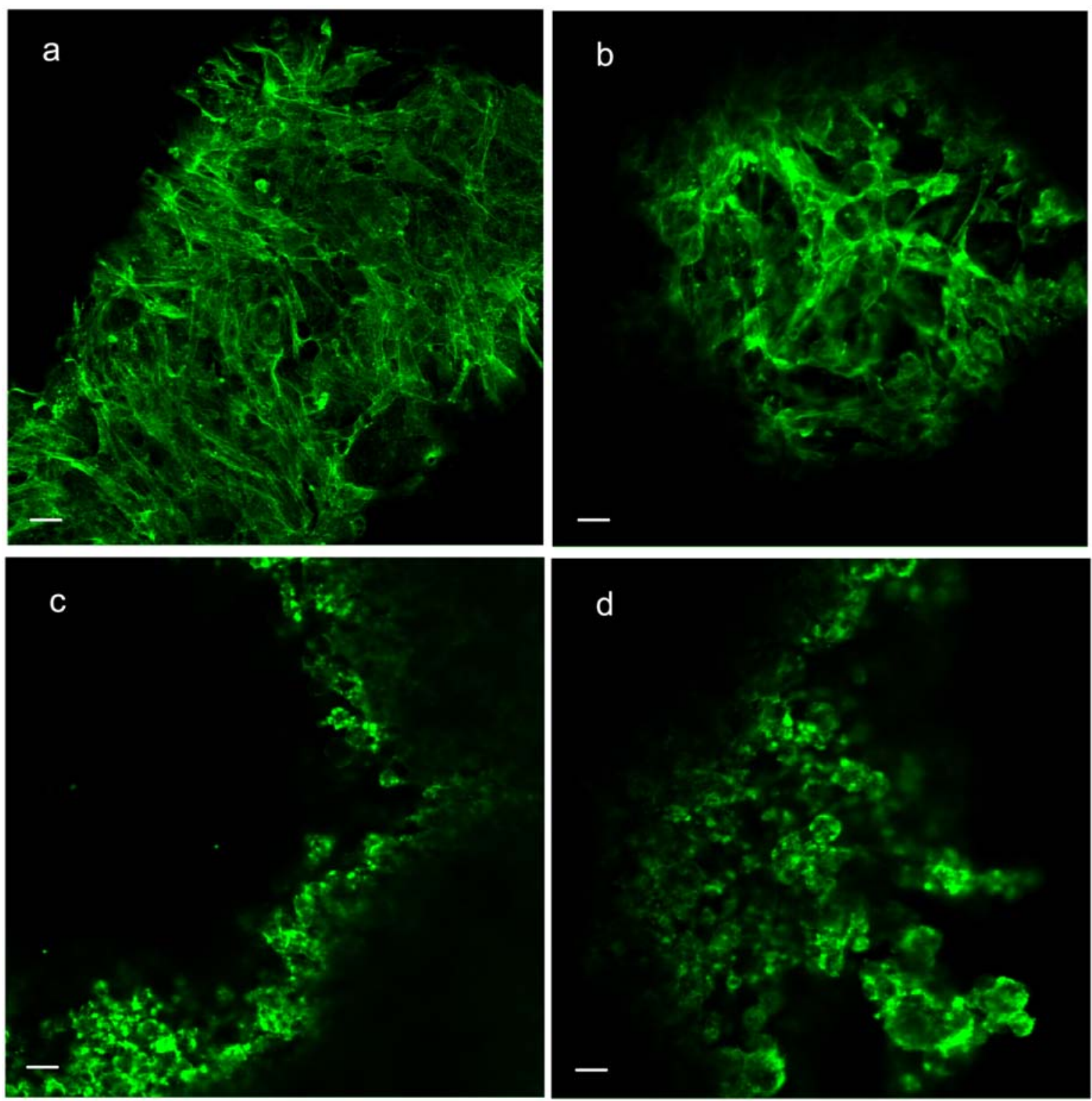

Fig. (4). Phalloidin staining of microfilaments in C3H10T1/2 cell pellet. (a) Control; (b) Pressure (5 MPa hydrostatic pressure applied at 1 $\mathrm{Hz}$ for $2 \mathrm{~h}$ ); (c) CSK Disrupting (4 $\mu \mathrm{M}$ cytochalasin D); (d) Combined (pressure + cytochalasin). Scale bars $=25 \mu \mathrm{m}$.

displayed prominent actin stress fibers and a fine filamentous network of microtubules. These structures were abolished by cytochalasin-D and nocodazole, respectively. Actin and tubulin appeared to be collapsed into globular clusters. Pellets subjected to hydrostatic pressure were more firm and did not flatten against the glass slide as much as the controls; hence the somewhat smaller and more circular but there were no other apparent effects of pressure on microfilaments or microtubules. Likewise, drug-treated pellets which had been pressurized had a similar appearance to their non-pressurized counterparts.

\section{DISCUSSION}

Tibiofemoral joint contact pressure is in the range of 3-11 MPa [24], over $90 \%$ of which is supported by interstitial fluid pressure $[25,26]$. Therefore much attention has been focused on hydrostatic loading as a means of promoting chondroinduction of mesenchymal stem cells. Indeed, many studies have confirmed that cyclic hydrostatic pressure can enhance chondrogenesis by primary bone marrow mesenchymal stem cells and C3H10T1/2 murine fibroblasts [1-6]. Cyclic pressurization to $0.1 \mathrm{MPa}$ is sufficient to enhance chondroinduction [27], and higher pressure magnitudes elicit a stronger response [28]. The prevailing theory of cartilage mechanobiology is based on the concept that intermittent hydrostatic pressure is the greatest stimulus for cartilage maintenance [29], and in vitro experiments have confirmed that intermittent hydrostatic pressure increases chondrocyte marker gene expression, macromolecule production, and extracellular matrix deposition by mesenchymal stem cells [1-6]. However, the cellular mechanisms by which mesenchymal stem cells transduce hydrostatic pressure remain largely unknown. The purpose of our study was to determine the importance of the cytoskeleton in mechanotransduction (transformation of an applied physical stimulus into a cellular biomolecular response) of hydrostatic pressure by 

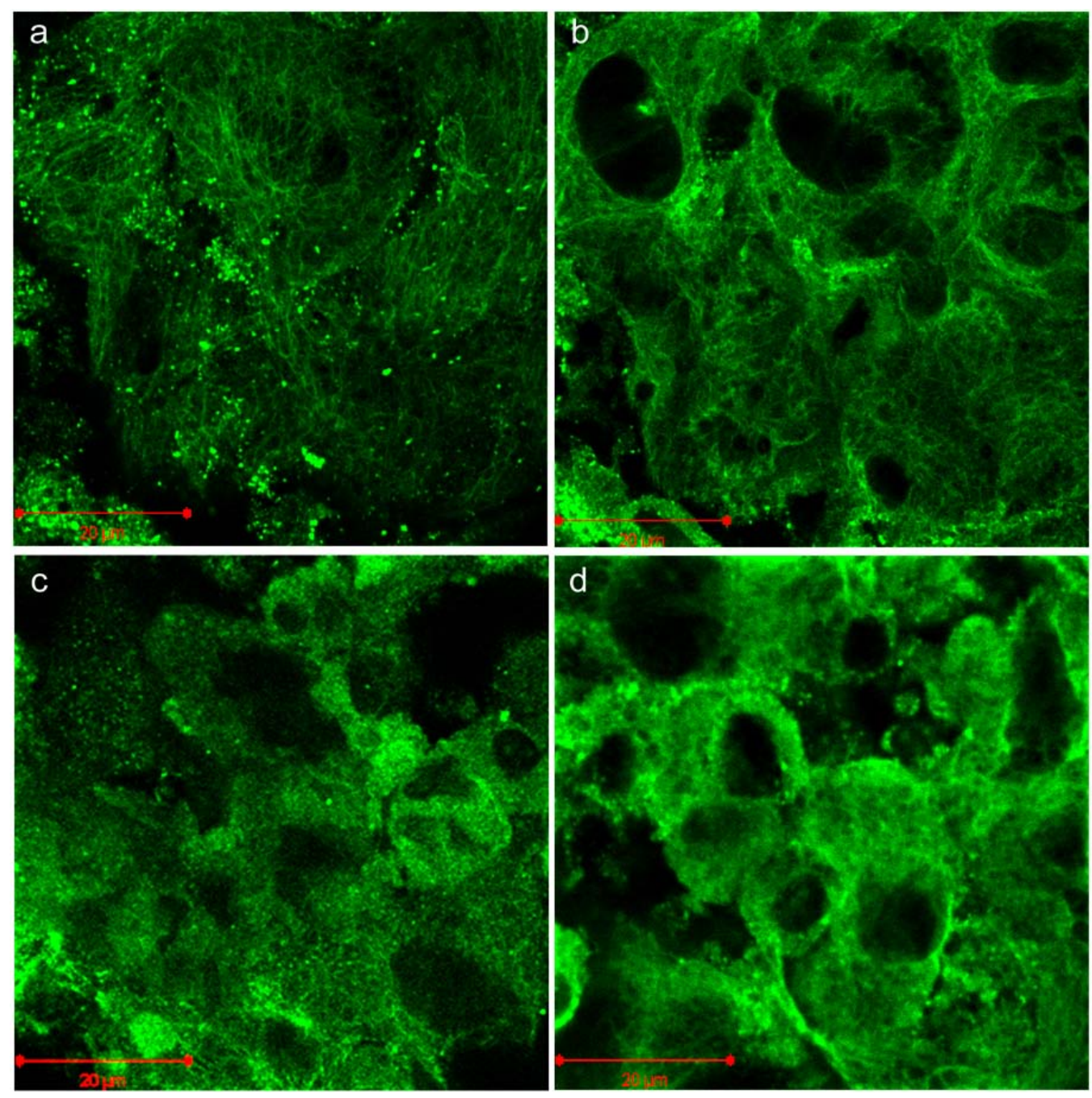

Fig. (5). Indirect fluorescent immunostaining of microtubules in C3H10T1/2 cell pellet. (a) Control; (b) Pressure (5 MPa hydrostatic pressure applied at $1 \mathrm{~Hz}$ for $2 \mathrm{~h}$ ); (c) CSK Disrupting (4 $\mu \mathrm{M}$ nocodazole); (d) Combined (pressure + nocodazole). Scale bars $=20 \mu \mathrm{m}$.

C3H10T1/2 murine fibroblasts, a model for primary bone marrow mesenchymal stem cells. Cells undergoing division, such as may occur in a healing osteochondral defect, a cellladen tissue engineering scaffold, or a bony fracture gap, will have an altered cytoskeleton. In addition, some anti-cancer drugs, such as vinblastine, work by interfering with cytoskeletal function. Knowledge gained through studies such as this may enhance our understanding of cartilage tissue engineering, fracture healing, potential anti-cancer drug side effects, and the etiology of osteoarthritis.

C3H10T1/2 cells were used as a model of bone marrow mesenchymal stem cells because of their homogeneity, rapid growth rate, low biosafety risk, and low cost. Previous studies of mesenchymal stem cell mechanobiology have examined the effects of hydrostatic pressure in the physiological range of 1-10 MPa applied at or near typical gait frequency of $1 \mathrm{~Hz}[1,3,4,6]$, and a similar loading regimen was utilized in the current study. Mechanotransduction was based on upregulation of aggrecan and type II collagen mRNA. Aggrecan and type II collagen are the most important structural components of articular cartilage and together they account for approximately two-thirds of its dry weight. Therefore they are widely used as markers of chondroinduction and chondrocyte biosynthetic activity. More importantly, the mechanosensitivity of aggrecan and type II collagen mRNA is well established, with substantial increases observed for both in response to hydrostatic pressure [3,6,21,30,31].

The cytoskeleton is known to mediate force transfer from the extracellular matrix to the nucleus [32] and has been implicated in mechanotransduction of several kinds of distortional stress, including shear [33], stretch [7], and compression [34]. But hydrostatic compression, pressure acting with equal magnitude in all directions, will not produce a change in cell shape; rather, it will tend to decrease the cell's volume. The cell can be considered to behave as a biphasic viscoelastic solid, with water as one phase and the cytoskeleton and organelles together making up the other. Such a structure is predicted to undergo minimal volumetric strain under hydrostatic loading. Although a decrease in chondrocyte volume has been observed under distortional compressive loading, this decrease was attributed to fluid exudation rather than compressibility of cellular components and cytoplasm [35], as Wilkes and Athanasiou [36] had previously reported on the intrinsic incompressibility of osteoblast-like cells.

Our study examines the effect of disrupting either microfilaments or microtubules on the hydrostatic pressure-induced 
increase in macromolecular gene expression in $\mathrm{C} 3 \mathrm{H} 10 \mathrm{~T} 1 / 2$ murine fibroblasts. We had previously tested the effects of cytochalasin D and nocodazole on the C3H10T1/2 microfilament and microtubule networks, respectively, and determined that $4 \mu \mathrm{M}$ was sufficient to achieve thorough disruption, as we observed in the present study. The selective action of these drugs has been verified by other investigators $[37,38]$. The combination of cytochalasin and nocodazole was somewhat cytotoxic, so experiments were not performed in the presence of both drugs. We found that treatment with either cytochalasin D or nocodazole drastically lowered aggrecan and col2a1 mRNA expression, which highlights the importance of the cytoskeleton in maintaining normal cell function.

Concerning the effects of nocodazole, our results are consistent with previous findings that it inhibits proteoglycan production by articular chondrocytes $[9,10]$. But in our study cells exposed to either drug responded to cyclic hydrostatic pressure of physiological magnitude $(5 \mathrm{MPa})$ by increasing expression of both genes above the drug-suppressed baseline. Furthermore, the magnitude of the increase was approximately the same as that observed in drug-free cells relative to drug-free controls. Our data contrast somewhat with those of Jortikka et al. [9]. They showed that microtubules mediated the proteoglycan biosynthetic response to 5 MPa cyclic hydrostatic pressure, as no stimulation of proteglycan secretion occurred in monolayer chondrocytes treated with nocodazole. There are many differences in the two models which could account for the apparent disparity, including the type of cells (transformed mesenchymal stem cells vs. primary articular chondrocytes) and culture configuration (monolayer vs. pellet). In addition, cellular strain due to deformation of the substrate is a possible confounding factor in their experiment. It is also possible that nocodazole does not inhibit a cells' ability to perceive the hydrostatic pressure and respond from a transcriptional standpoint, but does interferes with its ability to increase synthesis or secretion. In chondrocytes, nocodazole treatment was associated with fragmentation and dispersion of the Golgi apparatus [10], where glycosylation and sulphation of proteoglycans occurs. In a pattern similar to that which we observed, Bianchi et al. [39] found that actin- and microtubule-perturbing toxins inhibited EAAT3 glutamate transporter activity but did not prevent the phorbol ester-stimulated increase in transport from this lower basal activity level.

Future studies will be designed to determine if cytoskeleton perturbation interferes with the pressure-induced activation or mobilization of intercellular signaling molecules upstream of gene transcription. In summary, cytochalasin-D and nocodazole, which selectively disassemble microfilaments and microtubules, suppressed aggrecan and col2a1 mRNA expression in C3H10T1/2 cells. However, neither drug alone prevented the hydrostatic pressure-stimulated increase in macromolecule mRNA expression relative to the lowered basal level.

\section{ACKNOWLEDGEMENTS}

This research was supported by the Mississippi State Bagley College of Engineering. Technical support and equipment were provided by the Mississippi State Electron Microscope Center and the Mississippi State Life Sciences and Biotechnology Institute.

\section{REFERENCES}

[1] Angele P, Yoo JU, Smith C, et al. Cyclic hydrostatic pressure enhances the chondrogenic phenotype of human mesenchymal progenitor cells differentiated in vitro. J Orthop Res 2003; 21(3): 4517.

[2] Elder SH, Fulzele KS, McCulley WR. Cyclic hydrostatic compression stimulates chondroinduction of $\mathrm{C} 3 \mathrm{H} / 10 \mathrm{~T} 1 / 2$ cells. Biomech Model Mechanobiol 2005; 3(3): 141-6.

[3] Miyanishi K, Trindade MC, Lindsey DP, et al. Effects of hydrostatic pressure and transforming growth factor-beta 3 on adult human mesenchymal stem cell chondrogenesis in vitro. Tissue Eng 2006; 12(6): 1419-28.

[4] Finger AR, Sargent CY, Dulaney KO, Bernacki SH, Loboa EG. Differential effects on messenger ribonucleic acid expression by bone marrow-derived human mesenchymal stem cells seeded in agarose constructs due to ramped and steady applications of cyclic hydrostatic pressure. Tissue Eng 2007; 13(6): 1151-8.

[5] Luo ZJ, Seedhom BB. Light and low-frequency pulsatile hydrostatic pressure enhances extracellular matrix formation by bone marrow mesenchymal cells: an in vitro study with special reference to cartilage repair. Proc Inst Mech Eng [H] 2007; 221(5): 499-507.

[6] Wagner DR, Lindsey DP, Li KW, et al. Hydrostatic pressure enhances chondrogenic differentiation of human bone marrow stromal cells in osteochondrogenic medium. Ann Biomed Eng 2008; 36(5): 813-20.

[7] Trepat X, Deng L, An SS, et al. Universal physical responses to stretch in the living cell. Nature 2007; 447(7144): 592-5.

[8] Parkkinen JJ, Lammi MJ, Inkinen R, et al. Influence of short-term hydrostatic pressure on organization of stress fibers in cultured chondrocytes. J Orthop Res 1995; 13(4): 495-502.

[9] Jortikka MO, Parkkinen JJ, Inkinen RI, et al. The role of microtubules in the regulation of proteoglycan synthesis in chondrocytes under hydrostatic pressure. Arch Biochem Biophys 2000; 374(2): 172-80.

[10] Parkkinen JJ, Lammi MJ, Pelttari A, Helminen HJ, Tammi M, Virtanen I. Altered Golgi apparatus in hydrostatically loaded articular cartilage chondrocytes. Ann Rheum Dis 1993; 52(3): 192-8.

[11] Fioravanti A, Benetti D, Coppola G, Collodel G. Effect of continuous high hydrostatic pressure on the morphology and cytoskeleton of normal and osteoarthritic human chondrocytes cultivated in alginate gels. Clin Exp Rheumatol 2005; 23(6): 847-53.

[12] Guilak F. Compression-induced changes in the shape and volume of the chondrocyte nucleus. J Biomech 1995; 28(12): 1529-41.

[13] Pirttiniemi P, Kantomaa T. Effect of cytochalasin D on articular cartilage cell phenotype and shape in long-term organ culture. Eur J Orthod 1998; 20(5): 491-9.

[14] Clemen CS, Hofmann A, Zamparelli C, Noegel AA. Expression and localisation of annexin VII (synexin) isoforms in differentiating myoblasts. J Muscle Res Cell Motil 1999; 20(7): 669-79.

[15] Nakamura T, Aikawa T, Iwamoto-Enomoto M, et al. Induction of osteogenic differentiation by hedgehog proteins. Biochem Biophys Res Commun 1997; 237(2): 465-9.

[16] Wang EA, Israel DI, Kelly S, Luxenberg DP. Bone morphogenetic protein-2 causes commitment and differentiation in C3H10T1/2 and 3 T3 cells. Growth Factors 1993; 9(1): 57-71.

[17] Zehentner BK, Leser U, Burtscher H. BMP-2 and sonic hedgehog have contrary effects on adipocyte-like differentiation of C3H10T1/2 cells. DNA Cell Biol 2000; 19(5): 275-81.

[18] Denker AE, Nicoll SB, Tuan RS. Formation of cartilage-like spheroids by micromass cultures of murine $\mathrm{C} 3 \mathrm{H} 10 \mathrm{~T} 1 / 2$ cells upon treatment with transforming growth factor-beta 1. Differentiation 1995; 59(1): 25-34.

[19] Denker AE, Haas AR, Nicoll SB, Tuan RS. Chondrogenic differentiation of murine C3H10T1/2 multipotential mesenchymal cells: I. Stimulation by bone morphogenetic protein-2 in high-density micromass cultures. Differentiation 1999; 64(2): 67-76.

[20] Elder SH, Sanders SW, McCulley WR, Marr ML, Shim JW, Hasty KA. Chondrocyte response to cyclic hydrostatic pressure in alginate versus pellet culture. J Orthop Res 2006; 24(4): 740-7.

[21] Shim JW, Elder SH. Influence of cyclic hydrostatic pressure on fibrocartilaginous metaplasia of achilles tendon fibroblasts. Biomech Model Mechanobiol 2006; 5(4): 247-52.

[22] Rozen S, Skaletsky HJ. Primer3 on the WWW for general users and for biologist programmers. In: Krawetz S, Misener S Eds. Bioinformatics Methods and Protocols: Methods in Molecular Biology, Humana Press, 2000; 365-386. 
[23] Livak KJ, Schmittgen TD. Analysis of relative gene expression data using real-time quantitative PCR and the 2(-Delta Delta C(T)) Method. Methods 2001; 25: 402-8.

[24] Becher C, Huber R, Thermann H, Paessler HH, Skrbensky G. Effects of a contoured articular prosthetic device on tibiofemoral peak contact pressure: a biomechanical study. Knee Surg Sports Traumatol Arthrosc 2008; 16(1): 56-63.

[25] Park S, Krishnan R, Nicoll SB, Ateshian GA. Cartilage interstitial fluid load support in unconfined compression. J Biomech 2003; 36(12): 1785-96.

[26] Soltz MA, Ateshian GA. Interstitial fluid pressurization during confined compression cyclical loading of articular cartilage. Ann Biomed Eng 2000; 28(2): 150-9.

[27] Luo ZJ, Seedhom BB. Light and low-frequency pulsatile hydrostatic pressure enhances extracellular matrix formation by bone marrow mesenchymal cells: an in vitro study with special reference to cartilage repair. Proc Inst Mech Eng [H] 2007; 221(5): 499-507.

[28] Miyanishi K, Trindade MC, Lindsey DP, et al. Dose- and timedependent effects of cyclic hydrostatic pressure on transforming growth factor-beta3-induced chondrogenesis by adult human mesenchymal stem cells in vitro. Tissue Eng 2006; 12(8): 2253-62.

[29] Beaupre GS, Stevens SS, Carter DR. Mechanobiology in the development, maintenance, and degeneration of articular cartilage. J Rehabil Res Dev 2000; 37(2): 145-51.

[30] Smith RL, Lin J, Trindade MC, et al. Time-dependent effects of intermittent hydrostatic pressure on articular chondrocyte type II collagen and aggrecan mRNA expression. J Rehabil Res Dev 2000; 37(2): 153-61.

[31] Toyoda T, Seedhom BB, Kirkham J, Bonass WA. Upregulation of aggrecan and type II collagen mRNA expression in bovine chon- drocytes by the application of hydrostatic pressure. Biorheology 2003; 40(1-3): 79-85.

[32] Maniotis AJ, Chen CS, Ingber DE. Demonstration of mechanical connections between integrins, cytoskeletal filaments, and nucleoplasm that stabilize nuclear structure. Proc Natl Acad Sci USA 1997; 94(3): 849-54.

[33] Mazzag BM, Tamaresis JS, Barakat AI. A model for shear stress sensing and transmission in vascular endothelial cells. Biophys J 2003; 84(6): 4087-101.

[34] Li J, Chen G, Zheng L, Luo S, Zhao Z. Osteoblast cytoskeletal modulation in response to compressive stress at physiological levels. Mol Cell Biochem 2007; 304(1-2): 45-52.

[35] Trickey WR, Baaijens FP, Laursen TA, Alexopoulos LG, Guilak F. Determination of the Poisson's ratio of the cell: recovery properties of chondrocytes after release from complete micropipette aspiration. J Biomech 2006; 39(1): 78-87.

[36] Wilkes R, Athanasiou K The intrinsic incompressibility of osteoblast-like cells. Tissue Eng 1996; 2: 167-81.

[37] Colvin RA, Laskowski M, Fontaine CP. Zinquin identifies subcellular compartmentalization of zinc in cortical neurons. Relation to the trafficking of zinc and the mitochondrial compartment. Brain Res 2006; 1085(1): 1-10.

[38] Zegers MM, Zaal KJ, van IJzendoorn SC, Klappe K, Hoekstra D. Actin filaments and microtubules are involved in different membrane traffic pathways that transport sphingolipids to the apical surface of polarized HepG2 cells. Mol Biol Cell 1998; 9(7): 1939-49.

[39] Bianchi MG, Rotoli BM, Dall'Asta V, Gazzola GC, Gatti R, Bussolati O. PKC-dependent stimulation of EAAT3 glutamate transporter does not require the integrity of actin cytoskeleton. Neurochem Int 2006; 48(5): 341-9. 